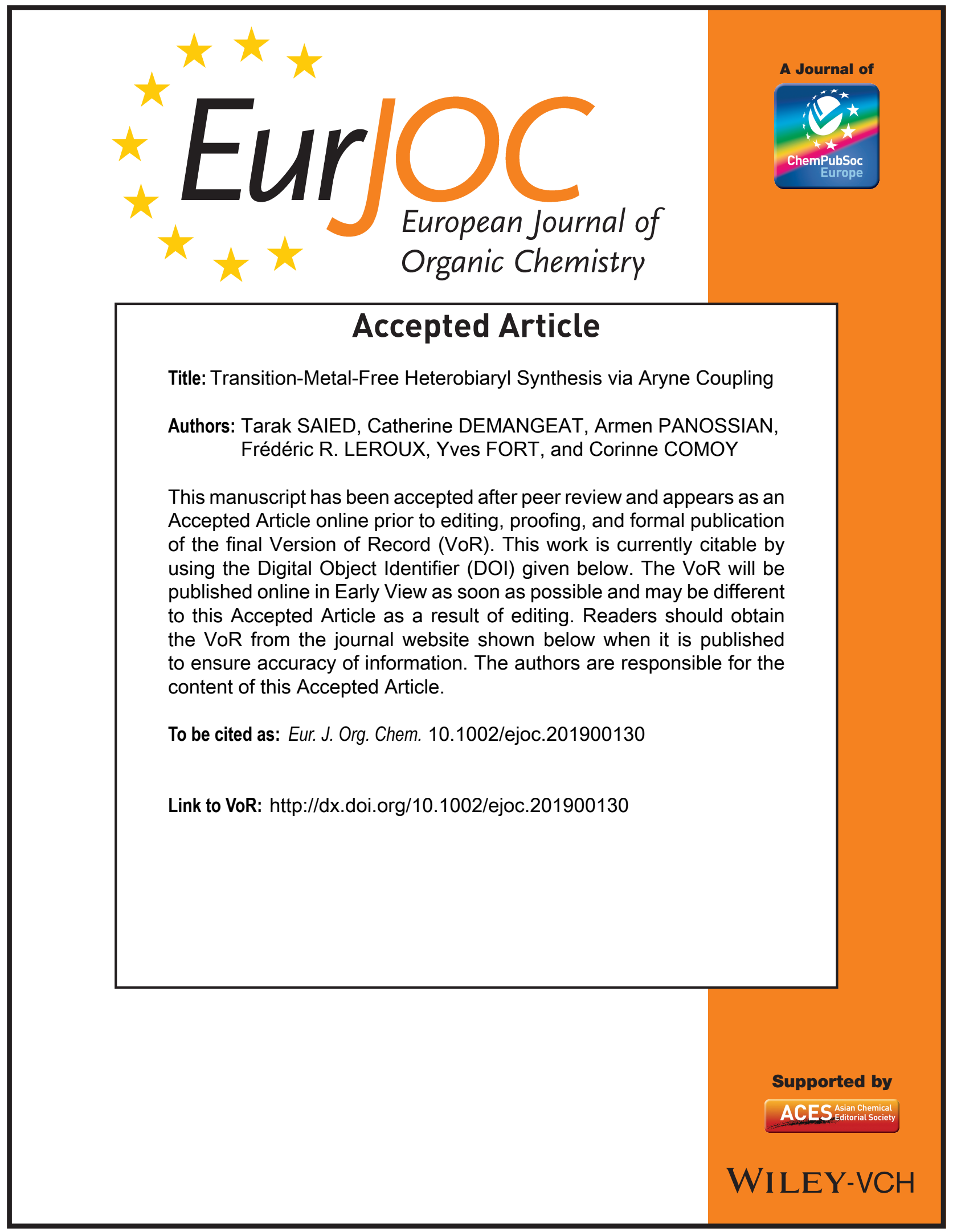




\title{
Transition-Metal-Free Heterobiaryl Synthesis via Aryne Coupling
}

\author{
Tarak Saied, ${ }^{[a]}$ Catherine Demangeat, ${ }^{[a]}$ Armen Panossian, ${ }^{[b]}$ Frédéric R. Leroux, ${ }^{[b]}$ Yves Fort, ${ }^{[a]}$ Corinne \\ Comoy*[a]
}

\begin{abstract}
We disclose for the first time an efficient route for the construction of various heterobiaryl backbones in fair to excellent yields using the Aryne coupling methodology. This study outlined the remarkable effect of external chelating ligands and salt additives on the heterocyclic partner reactivity in the aryne coupling reaction.
\end{abstract}

\section{Introduction}

The interest for heterobiaryls and their applications ${ }^{[1-4]}$ is a driving force for the continuous development of new synthetic methods towards theses peculiar structures. In comparison to the classical biaryl compounds, the presence of an heterocycle in the biaryl structure can provide attractive synthetic and biologic opportunities although this often complicates the coupling between the two (hetero)aromatic partners- a favoured synthetic methods for the construction. ${ }^{[5-8]}$ Indeed, the reduced reactivity of the substrate, the coordinating property of the heteroatom with the metal center of the catalyst where applicable, and the reduced configurational stability of the product usually make the access to these compounds more complicated, especially the chiral ones. ${ }^{[9-}$ 17]

Additionally, the unique reactivity of each type of heterocycles renders difficult the development of a general synthetic route compatible with a range of various heteroaryl containing compounds, and makes the simple extension of aryl-aryl coupling methods generally ineffective. ${ }^{[18-20]}$ Therefore, the development of an efficient method to construct hetaryl-aryl backbones is still a subject of high significance.

Recently, the drive for sustainable alternatives avoiding the use of expensive and potentially toxic transition metals has stimulated efforts for the development of metal-free "greener" synthetic methods, ${ }^{[21-23]}$ such as the direct arylation of heteroarenes. ${ }^{[7]}$ These processes often rely on radical-type mechanisms combining for example the use of aryl halides with a diaryliodonium salt ${ }^{[8,24]}$ or a metal-alkoxide with amine bases. ${ }^{[25-27]}$ However, these alternatives often require the use of the (hetero)arene coupling component in a very large molar excess and the regioselectivity of the arylation remains an important issue. In this context, Leroux et al. reported an efficient transition metal free aryl-aryl coupling protocol, the so-called "Aryne coupling"

[a] Université de Lorraine, CNRS, L2CM UMR7053 B.P. 70239,54506 Vandoeuvre-lès-Nancy, France corinne.comoy@univ-lorraine.fr

[b] Université de Strasbourg, Université de Haute-Alsace, CNRS, LIMA, UMR 7042, ECPM, 67000 Strasbourg

Supporting information for this article is given via a link at the end of the document. reaction. ${ }^{[28-43]}$ Very recently, we extended the reaction to the construction of hetaryl-aryl backbones, developing thus the "(Het)-Aryne" version of the reaction (scheme 1). ${ }^{[44]}$ However, our study essentially focused on the thiophene ring as a model partner. Thanks to experimental and theoretical investigations, we validated, particularly, a mechanism proposal and we highlighted significant effects of additives - ligand (dimethoxyethane, DME) and salt $(\mathrm{LiBr})$ - when performing the reaction in a noncoordinating solvent.

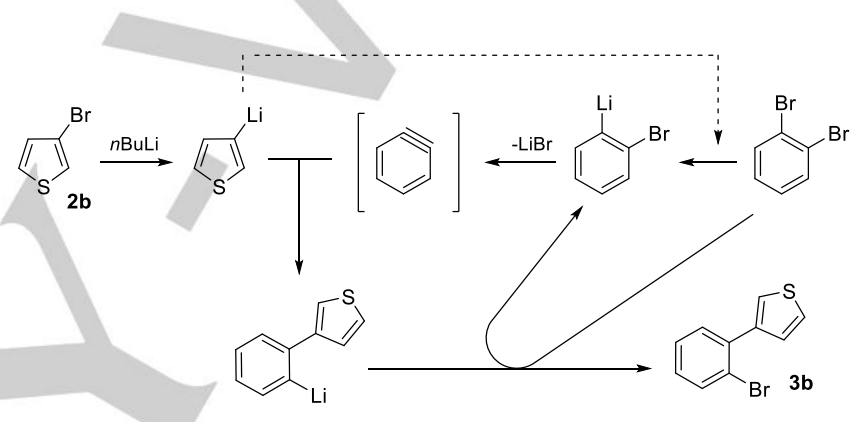

Scheme 1. Envisioned mechanism for the Aryne coupling of 3-bromothiophene and dibromobenzene.

Thus, based on our previous work, we envision here to extend the scope of this (Het)-Aryne coupling reaction to the construction of various hetaryl-aryl backbones, evaluating on the other hand the effect of a wide range of chelating ligands and salt additives on this sequence. Polar organometallic chemistry appeared as an ideal tool toward this aim, considering the high selectivity that can be achieved in a metalation process of heterocyclic systems. ${ }^{[45-47]}$ Indeed, directed metalation provides an interesting answer to the regioselectivity issue often encountered with the transition metalcatalyzed methodologies usually limiting the scope of the arylation to the most reactive position of the heterocycle.

\section{Results and Discussion}

We began this work by examining the extension of the scope of the heteroarene coupling partner in the (Het)-Aryne coupling previously developed by our group. ${ }^{[44]}$ To this end, we decided to study three (hetero)-aromatic series (Table 1) in order to evaluate the electronic influence of the heteroaromatic lithiated partner generated in the aryne coupling: first, $\pi$-deficient systems represented by the popular pyridinic moiety-, second, some $\pi$ electron-rich systems - with a more specific focus on thiophene derivatives - and last, two electron-neutral aromatic derivatives being used as references. Note that, in parallel, several metalation routes were envisioned for the formation of lithiated 
partners in order to obtain further insight on the influence of the basic system employed during the aryne coupling. To facilitate the cross-comparison of results, we initiated this work using a uniform set of experimental conditions (Table 1) derived from those originally developed with precursor $1 \mathrm{a}$ for the coupling step, ${ }^{[44]}$ as described hereafter. Thus, our first attempts were carried out by adding 1,2-dibromobenzene $1 \mathrm{a}$ (1.2 equiv.) at $-50{ }^{\circ} \mathrm{C}$ on the lithiated heteroaromatic partner [2a-j-Li] (1.0 equiv.) previously formed and using tetrahydrofuran (THF) as solvent. The resulting mixture was quenched at this temperature after $2 \mathrm{~h}$ of reaction time.

Table 1. Heteroarene pronucleophile partners in the Het-Aryne coupling reaction

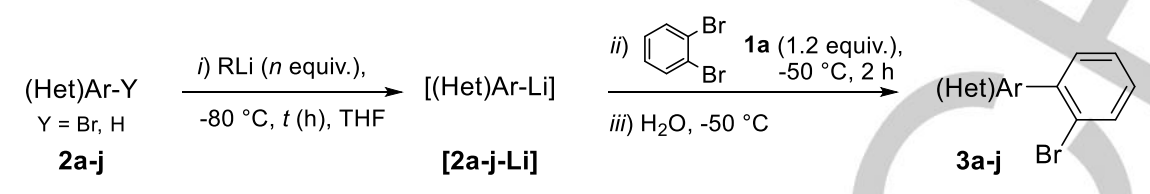

(3)

[a] Isolated yields after centrifugal thin-layer chromatography purification. [b] Metalation was performed using $\mathrm{BF}_{3} . \mathrm{Et}_{2} \mathrm{O}$ (1.0 equiv.) as an activator for the heteroarene. ${ }^{[48,49]}$ [c] $A$ commercial solution of $\mathrm{PhLi}(1.8 \mathrm{M})$ in cyclohexane/ndibutylether: $7 / 3$ was used.

The arylation scope with respect to the heteroaromatic partner is shown Table 1. Several interesting results already stood out from this exploratory study. First, the favorable influence of electronrich systems on the (Het)-Aryne coupling seemed to clearly emerge as a general trend. Accordingly, $\pi$ electron-rich systems 2a-d were found to furnish the best results, affording the expected heterobiaryls 3a-d in 41-60\% yield (entries 1-4, Table 1). Whereas only up to $26 \%$ yield of the aryl-pyridinic products $3 \mathrm{e}-\mathrm{h}$ were achieved in the $\pi$-deficient series (entries 5-8, Table 1), the "standard" aryl substrates $2 \mathbf{i}-\mathbf{j}$ led to the desired biaryl products $3 \mathbf{i}$-j in moderate yields (38-44\%, entries 9-10, Table 1 ).

The reduced size of the enriched heteroaromatic systems could also have an effect. Indeed, lower yields were obtained when the reaction was performed with the fused analogs of thiophene (3c $41 \%$ and 3 d $45 \%$ versus 3 b $60 \%$, entries $3-4,5$, Table 1 ). Especially, when the electron-poor pyridine ring was associated 
WILEY-VCH

to the furan one, only traces of the expected product $3 \mathbf{e}$ were detected (entry 5, Table 1), i.e. lower amounts than those obtained with either the naked pyridine (3f, $26 \%$, entry 6 , Table 1 ) or furan $(3 \mathbf{a}, 55 \%$, entry 1$)$. Subsequently, to improve the reactivity of the pyridine ring and facilitate its addition onto the aryne intermediate, we performed the Het-Aryne coupling using the more enriched 4-dimethylaminopyridine (DMAP) $\mathbf{2 g}$. Unfortunately, the expected product $\mathbf{3} \mathbf{g}$ was isolated only in a low $15 \%$ yield, for a conversion rate of $75 \%$ (entry 7 , Table 1) indicating that other factors have presumably to be considered. It is noteworthy that the formation of the aryne intermediate appears to have occurred since GC-MS analysis of the reaction mixture revealed the presence of two main products resulting from the competitive addition of the starting material DMAP $\mathbf{2 g}$ after lithiation or of excess lithium 2,2,6,6-tetramethylpiperidide (LiTMP), used as the lithiated base, onto benzyne. The latter hypothesis has been plainly demonstrated when lithium diisopropylamide (LDA) was employed in the metalation step starting from 3 -chloropyridine $\mathbf{2 h}$ (entry 8 , Table 1 ). Under these conditions, the reaction led exclusively to the addition product of diisopropylamine (DIA) on benzyne demonstrating the much higher reactivity of lithium amides in comparison to that of the generated lithiated pyridine [2f-h-Li]. Although the reaction of primary and secondary amines with arynes has been well established, ${ }^{[50,51]}$ addition of tertiary amines to arynes is only scarcely described in the literature, ${ }^{[52-54]}$ and was far less expected with regard to the concomitant presence of the lithiated species.

Based on our previous investigation regarding the remarkable effect of the chelating DME in a non-coordinating solvent on the coupling reaction of 3 -bromothiophene $\mathbf{2} \mathbf{b},{ }^{[44]}$ we decided then to evaluate the influence of this additive when added to the reaction of 3-bromopyridine $2 \mathbf{f}$ and bromobenzene $2 \mathbf{j}$ using toluene as solvent (Table 2). We found that the conversion rates are very close to the reaction yields, which proves that lithiation constitutes the limiting step for aryne couplings and that all the lithiated intermediates formed $[\mathbf{2} \mathbf{b}, \mathbf{f}, \mathbf{j}$ - $\mathbf{L i}]$ react with the precursor $\mathbf{1 a}$. The absence of conversion in toluene - both in absence and in presence of the benzyne precursor-confirms well this theory. The main observed by-products have been identified as products resulting from the reduction of the dihalogenoaryl precursor and / or the substrate as well as "homocoupling" products from precursor $\mathbf{1 a}$.

Table 2. Solvent and additive influence in Het-Aryne coupling reaction.

(Het)Ar-Br

[a] Conversion rates and isolated yields after centrifugal thin-layer chromatography purification. [b] A commercial solution of PhLi (1.8 M) in cyclohexane/ndibutylether: $7 / 3$ was used.

In comparison to the results reported for 3-bromothiophene $\mathbf{2 b}$ (entries 1-2, Table 2), the beneficial effect of the ligand was also observed with 3-bromopyridine $\mathbf{2 f}$ and bromobenzene $\mathbf{2 j}$ (entries 3-6, Table 2). From these results, it could be reasonable to speculate that DME strongly promotes the bromine-lithium exchange required for the formation of the lithiated partners [2b,f,j-Li] using tBuLi as base (2.0 equiv.) when carried out in toluene/DME, and probably to a lesser extent, those required for 
WILEY-VCH

the coupling step too, as already discussed in a preliminary work. ${ }^{[44]}$ In addition, the complete absence of "homocoupling" product from 1a when the reaction was carried out in toluene as solvent, may be consistent with this hypothesis.

Based on these results, we decided to explore in detail the ligand scope of the model reaction formerly developed with thiophene. Since DME (LA1) proved to furnish encouraging results, we first investigated the use of its structural analogs LB1, LC1 and LD1 (Table 3), based on a simple ethylene bridge, that is forming a five membered ring upon chelation with the organolithium, ${ }^{[55-57]}$ in order to evaluate the effect of the coordinating heteroatom nature. Comparisons of the results obtained with ligands LA1, LB1, LC1 and LD1 already provide some relevant information. First, replacement of the two coordinating O-atoms of DME by two nitrogen ones seemed to dramatically affect the reaction, since only a disappointing $6 \%$ yield was obtained when using the diamine TMEDA (LD1). This unfavorable influence of TMEDA on the aryne coupling is consistent with the reported results in the biphenyl series. ${ }^{[39]}$ In contrast, use of its aminoalkoxide analog, $D^{D M A E}{ }^{[58-61]}$ (LC1) afforded the expected heterobiaryl in a slightly better - but still modest $-20 \%$ yield. Although one could have expected a favorable influence of the alkoxide moiety, the reaction failed to occur when using the corresponding dialkoxide ligand LB1.

Table 3. Screening of various polydentate ligands in the Het-Aryne coupling reaction.

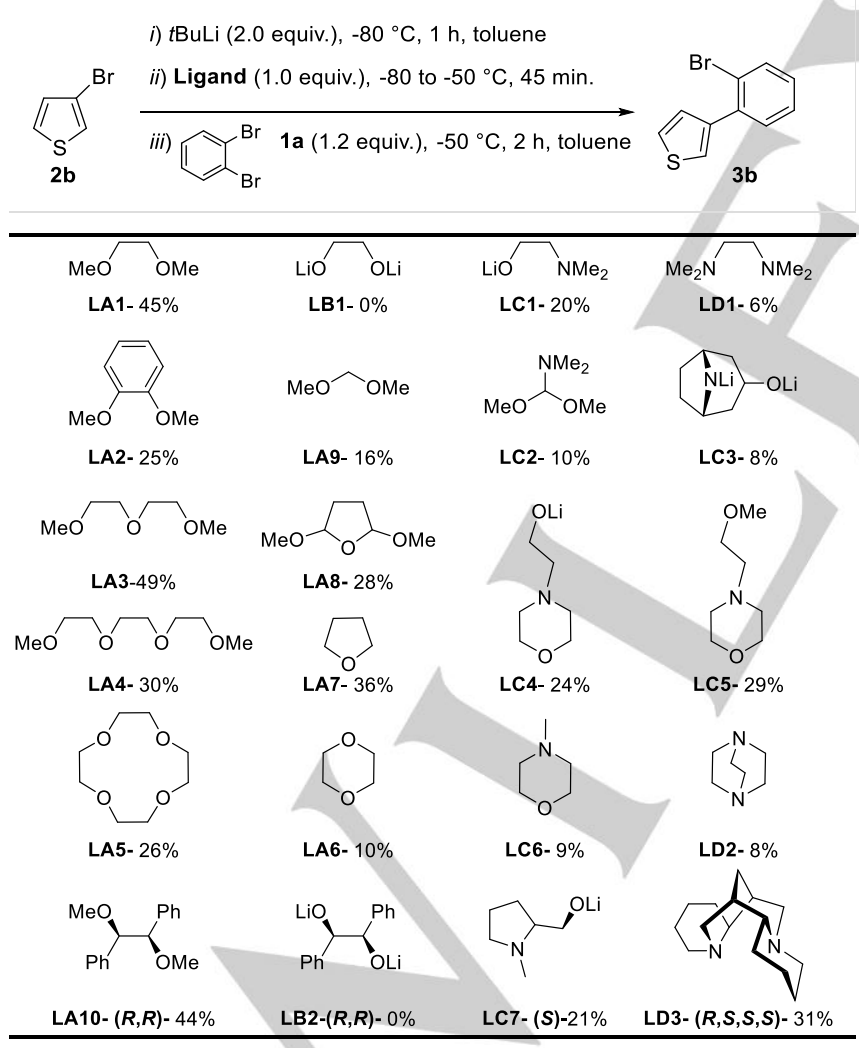

[a] Isolated yields after centrifugal thin-layer chromatography purification.

Overall, since none of these analogs provided yields as good as that obtained for DME, we next decided to examine a set of various ethers and polyethers as ligands to evaluate the structural effect of these compounds on the coupling reaction. Considering still the bidentate skeleton of DME, use of the more rigid diether LA2 gave the expected product $\mathbf{3 b}$ in a lower $25 \%$ yield, suggesting the relevance of the possible fluxional ability of LA1. Afterwards, the effect of the number of coordinating O-atoms in the ligand was examined. Interestingly, while polyether LA3 (diglyme) - three coordinating O-atoms - slightly improved the yield (49\%), LA4 (triglyme) - four coordinating O-atoms - was not favorable, and gave $\mathbf{3 b}$ in a lower $30 \%$ yield. Then, considering an identical number of coordinating O-atoms, comparison of LA4 to its related cyclic analog LA5 only revealed minor influence of the 12-crown-4 ether, although a "macrocyclic effect" could have been expected. ${ }^{[62,63]}$ In contrast, reducing the cycle size of LA5 leading to LA6, the cyclic analog of DME - dropped significantly the yield $(10 \%)$. Although the conformational constraint of the dioxane molecule could have been invoked, it is important to note that the weak solubility of this compound urged us to consider this result carefully. On the other hand, substituting the coordinating O-atom of dioxane by one (LC6, 9\%) or two nitrogen atoms (LD2, $8 \%)$ has no beneficial effect. Yet, further branching of the morpholine $\mathrm{N}$-atom with an alkoxy- (LC4) or a methoxydiethylene(LC5) side chain proved to be effective and produced comparable yields ( 24 and $29 \%$ respectively) to that obtained for the related aminoalkoxide LC1.

Overall, it seems reasonable to suggest that a diethereal ligand seems more favorable to the reaction than an alkoxide one, and definitely more advantageous than a tertiary amino ligand. It is interesting to note that a close parallel may be drawn between the inhibition of the reaction earlier encountered with DMAP $\mathbf{2 g}$ (Table 2 ), and the relative hindrance displayed herein by amine- and alkoxide-based ligands. Similarly to our previous hypothesis, our suspicion suggesting the major product to be the result of the addition of the ligand onto the transient aryne was once again in line with results emerging from GC-MS experiments. Such adducts were quite clearly identified with TMEDA (LD1), DABCO (LD2) or DMAE (LC1) as ligands, leading either to the corresponding salt or polyaddition product. These outcomes clearly demonstrate the high sensitivity of the Het-Aryne coupling towards the presence of various external nucleophiles.

Additionally, use of the simple THF ether LA7 as ligand provided the expected heterobiaryl in an interesting $36 \%$ yield. However, increasing the number of the coordinating O-atoms to three did not improve the yield (LA8, 28\%) which remained quite far from that obtained with ligand LA3 (49\%) featuring an identical coordinating O-atom number. The probable importance of the spacing between the coordinating atoms on the effectiveness of the ligand was confirmed by the result obtained with dimethoxymethane LA9 (16\%).

Last but not least, with asymmetric reactions in view, we screened a small set of external chiral ligands in connection with ligands LA1, LB1, LC1 and LD1 earlier examined. Especially, Tomioka's diether LA10 and the naturally occurring chiral diamine (-)sparteine LD3 were of special interest in view of their successful use already demonstrated in organolithium chemistry. ${ }^{[55,64-70]}$ Remarkably, employing the aforementioned chiral diether LA10 provided the expected product in a reasonable $44 \%$ yield - almost matching that of DME - despite the higher crowding displayed by this ligand. In sharp contrast, the dialkoxide analog LB2 of Tomioka's diether did not allow the reaction to occur. Likewise, use of LC7 afforded the expected heterobiaryl $\mathbf{3 b}$ in comparable results $(20 \%)$ to those obtained previously in the related achiral 
WILEY-VCH

series. Finally, a surprising $31 \%$ yield was reached when the benchmark ligand sparteine LD3 was employed, overshooting the previous results recorded with achiral diamine ligands. This surprising result could be attributed to the higher steric bulk of (-)sparteine as compared to that of diamines LD1 and LD2, possibly impeding the nucleophilic addition of this ligand onto the aryne. Considering the best ligands, LA1, 3, 7, 10, we next focused on further optimizing reaction conditions by varying the stoichiometry of the ligand. As shown in Table 4, it is clear from these results that the use of an increased amount of ligand had a beneficial effect on the yield. Remarkably, when DME and its related analog diglyme were used, a very similar trend was revealed when rising the amount of ligand from 0.5 to 10 equiv.

As reported for DME, the use of a substoichiometric amount of ligand seemed to dramatically affect the reaction. Overall, it appeared that 4 equiv. of ligand proved to be optimal (entries 5 , 10 and 14, Table 4). However, better yields were not achieved when an increased amount of ligand (10 equiv.) was employed. It is worthy to note that a close relationship between the yield and the number of coordinating O-atoms in connection with the amount of ligand used can be relatively well established when considering DME (LA1) and diglyme (LA3) ligands. Some results obtained with THF (LA7, entry 16, Table 4) and Tomioka's diether (LA10, entry 13, Table 4) are fairly consistent with this hypothesis.

Table 4. Effect of ligand stoichiometry on Het-Aryne coupling.

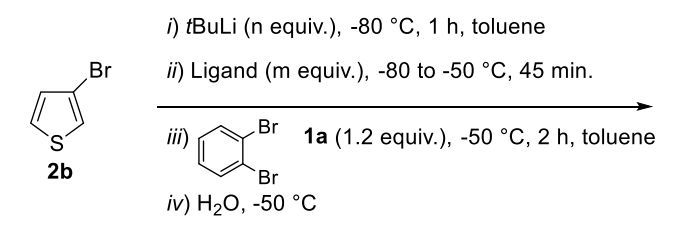

entry

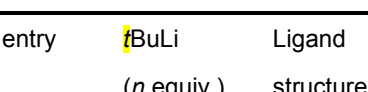

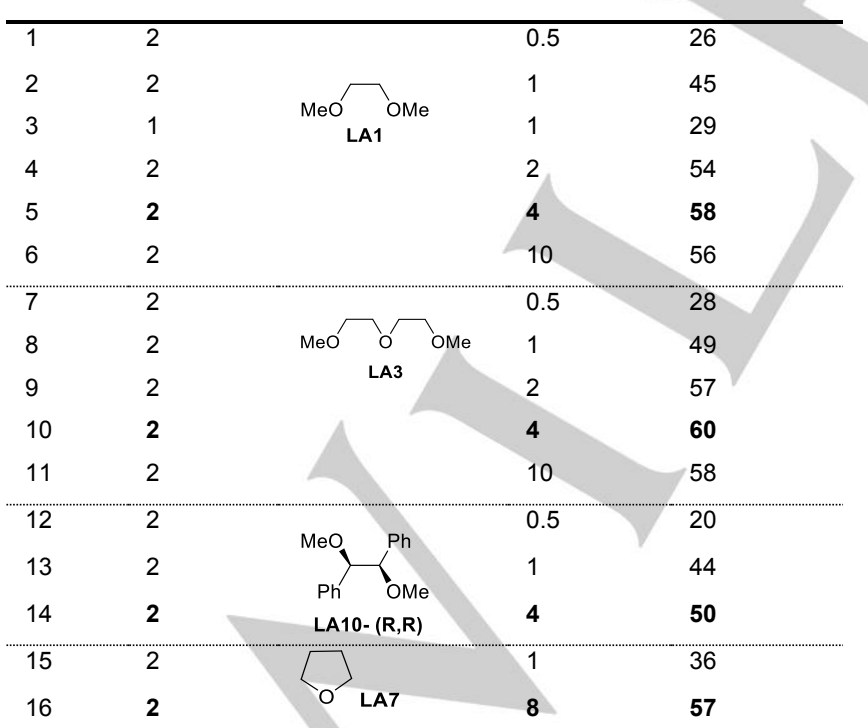

[a] Isolated yields after centrifugal thin-layer chromatography purification.

However, it seemed that there is no obvious correlation when other amounts or ligands are used which makes detailed interpretation difficult. Then, in order to further optimize the reaction conditions, we investigated the use of several aryne precursors 1a-d (Table 5) to extend the scope of the model reaction in toluene, keeping in mind the possible influence of the nature of the salt generated in the reaction. Note that, the use of 4.0 equiv. of DME will now be considered as the "standard conditions" when the reaction is carried out in toluene. Although slightly better results were achieved when using the diglyme ligand, DME was by far more accessible and cheaper, therefore we focused on this compound for the following study.

As illustrated in table 5, moving from the dibrominated aryne precursor $\mathbf{1 a}$ to its related analogs $\mathbf{1 b}-\mathbf{d}$ gave rise to considerable improvements of the yield. Especially, the iodinated analog $\mathbf{1 b}$ afforded the expected product $\mathbf{5 b}$ in a very good $75 \%$ yield and proved to be the best partner of the series. Interestingly, the serious increase of the yield observed when replacing a bromine atom by an iodine one have already been described in the biphenyl series and could be explained by the much faster iodine/lithium exchange occurring with this atom as compared to that with the bromine one. ${ }^{[38-40]}$

Table 5. Influence of the aryne precursor on the model reaction using DME as ligand.

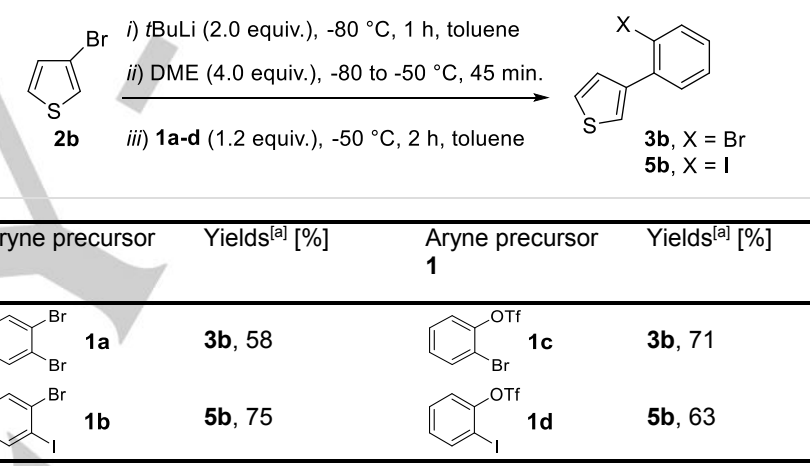

[a] Isolated yields after centrifugal thin-layer chromatography purification.

Nevertheless, the result obtained with $1 \mathbf{d}$ was not as high as we could have imagined especially when considering the impressive enhancement furnished by the related brominated analog 1c. Finally, it has to be noted that either $\mathrm{LiBr}$ or LiOTf released during the aryne formation did not affect the reaction, although the effect of this salt remains delicate to comment because it is accumulated all along the coupling step.

The idea of controlling organolithium reactivity and selectivity by altering the structure of organometallic aggregates is not new and has been fully exploited over the past decades. The previous investigation evaluating the effect of ligands clearly underlined influences of such compounds on the reactivity of organolithiums. ${ }^{[44]}$ In this context, "salt effects" have attracted significant interest in recent years, leading to comprehensive spectroscopic and theoretical investigations, ${ }^{[71-81]}$ more specifically in organolithium chemistry where the effects of lithium halides are commonly encountered. ${ }^{[82-95]}$ Lithium salts are undoubtedly among the most widely studied salts, being ubiquitous in a large number of lithiation reactions - either because they are generated in the reaction, or because they are involuntarily brought by a contaminated commercial source. Consequently, many reports investigated lithium halides and more particularly lithium chloride. In contrast, far less investigations were conducted on other alkaline or transition metal salts, often encountered however in cross-coupling 
WILEY-VCH

reactions. Especially, the use of these salts in lithiation reactions has been only scarcely described in literature, nor has been reported their employment in aryne chemistry. For these reasons, in addition to the classical lithium halide salts, the next part of this study investigated the effect of various alkaline and transition metal salts on the aryne coupling reaction.

In a previous study, ${ }^{[44]}$ we proved the positive influence of added $\mathrm{LiBr}$, which is also the spontaneously generated salt in the medium upon use of 1,2-dibromobenzene $1 \mathrm{a}$ as aryne precursor, on the reaction yield. These results encouraged us to explore the effect of other salts to further improve coupling conditions. We began by investigating the use of different amounts of lithium, potassium and cesium halides in the salt-free method using $n \mathrm{BuLi}$ as base, at $-40{ }^{\circ} \mathrm{C}$ for the lithiation of $\mathbf{2 b}$ (Table 6) that allow to avoid the concomitant presence of $\mathrm{LiBr}$. Indeed, contrarily to tBuLi, the use of one equivalent of $n \mathrm{BuLi}$ as a base does not generate LiX salt in the medium, which allows for studying the influence of the added salt only. It appeared from our previous study that 2, 5 and 10 equiv. seemed to us the most pertinent values to evaluate the effect of such salts when added to the reaction.

Table 6. Salt influence on the model Het-Aryne coupling reaction.

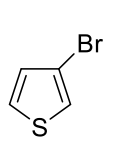

2 b i) $n \mathrm{BuLi}$ ( 1.0 equiv.), $-40^{\circ} \mathrm{C}$, $1 \mathrm{~h}$, toluene

ii) $\mathrm{MX}$ salt ( $n$ equiv.), $-40{ }^{\circ} \mathrm{C}, 5 \mathrm{~min}$.

iii) DME (4.0 equiv.), -40 to $-50{ }^{\circ} \mathrm{C}$

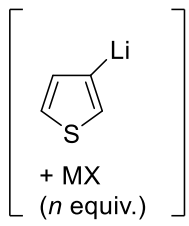

iv) $\mathbf{1} \mathbf{a}$ or $\mathbf{1 b}$ (1.2 equiv.),

$-50{ }^{\circ} \mathrm{C}, 2 \mathrm{~h}$, toluene

v) $\mathrm{H}_{2} \mathrm{O},-50^{\circ} \mathrm{C}$

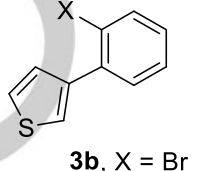

$3 \mathbf{b}, \mathrm{X}=\mathrm{Br}$

$5 b, X=1$

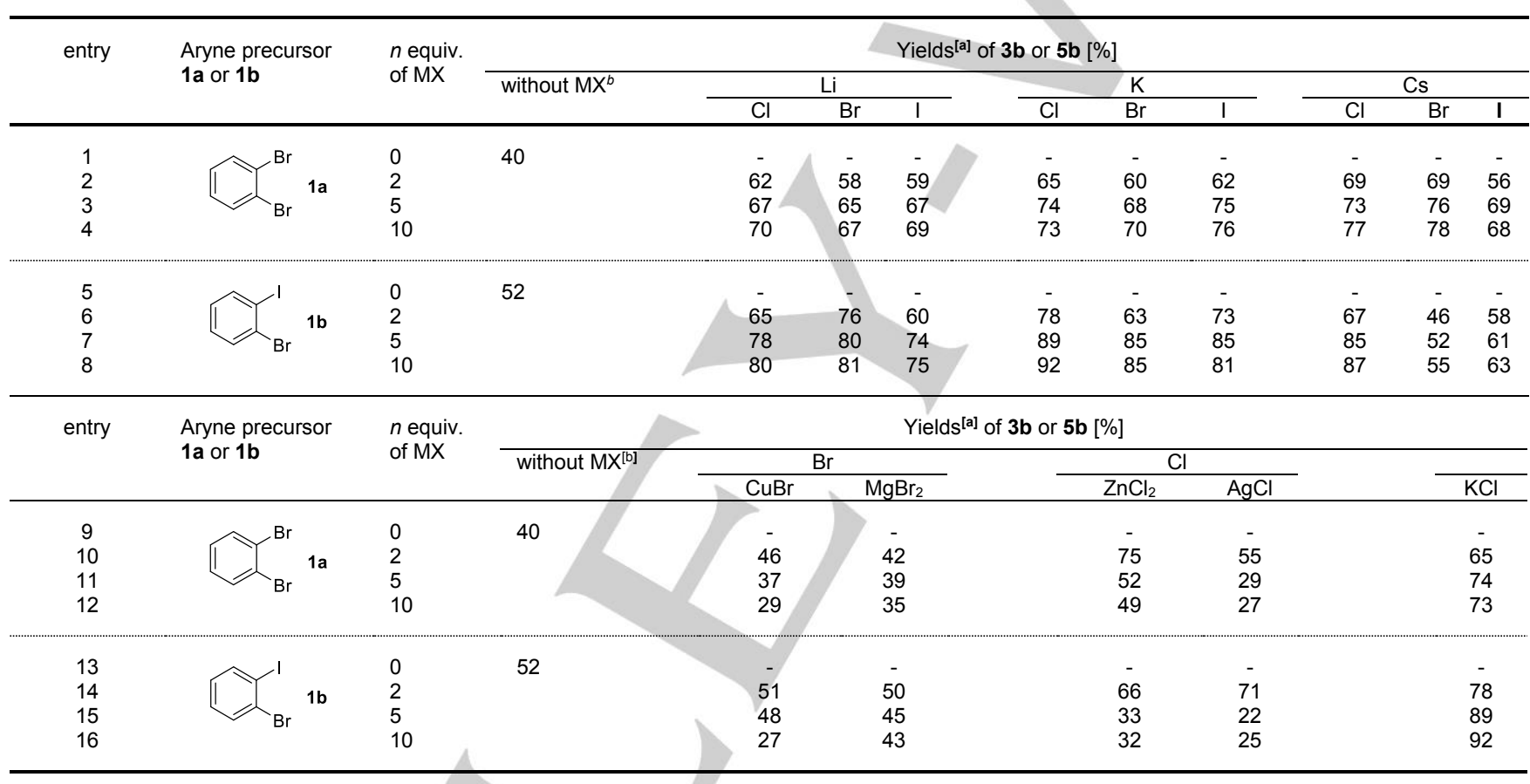

[a] Isolated yields after centrifugal thin-layer chromatography purification. [b] Isolated yields after centrifugal thin-layer chromatography purification when toluene was used as solvent, with DME as additive without salt.

We used either the model precursor $\mathbf{1 a}$ or its iodinated analog $\mathbf{1 b}$, for which better results were obtained. The results show that the use of an increased amount of salt had globally a beneficial effect on the yield. Potassium and cesium halides, especially, furnished the best results. Few improvements were noticed when the salt was employed in a large excess (10 equiv.) and it appeared overall that 5.0 equiv. of $\mathrm{KCl}$ proved to be the optimal additive. Furthermore, the ease of handling and the attractive cost of this additive were an advantage.

As the cation effect could be interesting, we investigated then the use of copper, magnesium, zinc and silver halides following the same procedure (entries 9-16, Table 6) to assess the effect of transition-metal salts and divalent species on the reaction. Comparison of these results to those obtained previously for $\mathrm{KCl}$ did not show further improvement. The general trend emerging from this study was clearly contrasting with that reported discussed above (entries 1-8) since a decrease of the yield was observed when an increased amount of salt was added to the reaction. Therefore, we did not further investigate the use of these salts.

From the above results, the ultimate goal of our study was to assess the effectiveness of ligand and salt on the coupling of other (hetero)aromatic partners in order to evaluate if additional improvement of preliminary results (see Table 1) could be expected. In this way, we used the optimized conditions obtained for the aryne precursor $\mathbf{1 b}$ : use of DME (4.0 equiv.) and $\mathrm{KCl}(5.0$ equiv.) as additives in toluene. $n \mathrm{BuLi}$ was used as the base, except for the pyridine derivative for which the use of $t \mathrm{BuLi}$ was inevitable. The results are gathered in Table 7. Yields of hetaryl compounds (3) previously obtained with the dibrominated precursor $\mathbf{1 b}$ were recalled for the sake of comparison. 
WILEY-VCH

It clearly appears that the optimized procedure developed with 3bromothiophene $\mathbf{2} \mathbf{b}$ could be generalized to other (halogenated)heterocyclic systems. The most spectacular achievement was the results obtained starting from 3-bromopyridine $\mathbf{2 f}$, for which the yield increased from 26 to $72 \%$. Improvements were also revealed for benzo[ $b]$ thiophene $\mathbf{2} \mathbf{d}$ and benzene $\mathbf{2} \mathbf{i}$-j derivatives but not for furopyridine 2e (entries 3, 6-7 and 4 respectively). Overall, it appeared that the electronic enrichment of the aromatic nucleophile seemed to have less influence on the outcome of the reaction than earlier reported for $\mathbf{1 a}$. Given the high dependency displayed previously by salts with the nature of the aryne precursor - and more generally, the high sensitivity of such additives to any species susceptible to interact with them - it is highly probable that the effect of $\mathrm{KCl}$ salt on the course of the reaction was also strongly dependent on the nature of the heterocyclic partner.

Table 7. Extension of the optimized Het-Aryne coupling conditions evaluating the effect of ligand and salt.

\begin{abstract}
i) RLi ( $n$ equiv.), $T\left({ }^{\circ} \mathrm{C}\right), t(\mathrm{~h})$, toluene
ii) $\mathrm{KCl}\left(5.0\right.$ equiv.), $T^{\circ} \mathrm{C}, 5 \mathrm{~min}$.
\end{abstract}

(Het)Ar-Y

$\mathrm{Y}=\mathrm{Br}, \mathrm{H}$

2a-k iii) DME (4.0 equiv.), $T^{\circ} \mathrm{C}$ to $-50^{\circ} \mathrm{C}, 45 \mathrm{~min}$.

iv) $1 \mathrm{~b}(1.2$ equiv. $),-50^{\circ} \mathrm{C}, 2 \mathrm{~h}$

v) $\mathrm{H}_{2} \mathrm{O},-50{ }^{\circ} \mathrm{C}$

\begin{tabular}{|c|c|c|c|c|c|c|c|}
\hline \multirow[t]{2}{*}{ entry } & \multirow[t]{2}{*}{ (Het)Ar-Y 2a-j } & \multicolumn{3}{|c|}{ Metalation conditions } & \multirow[t]{2}{*}{ Products 5a-g } & & \multirow{2}{*}{$\begin{array}{l}\text { Yields }^{[\mathrm{a}]}[\%] \\
\text { 5a-g }(\mathbf{3 a - g})\end{array}$} \\
\hline & & RLi ( $n$ equiv.) & $T\left({ }^{\circ} \mathrm{C}\right)$ & $t(\mathrm{~h})$ & & & \\
\hline 1 & $2 a$ & nBuLi (1.0 equiv.) & -80 & 1 & & $5 a$ & $61(55)$ \\
\hline 2 & 2 & $n$ BuLi (1.0 equiv.) & -40 & 1 & & $5 b$ & $89(60)$ \\
\hline 3 & 2 & $n$ BuLi (1.2 equiv.) & & & & & $61(45)$ \\
\hline 4 & $2 e$ & $n$ BuLi (1.2 equiv.) & 0 & 1 & & $5 e$ & $<5$ \\
\hline 5 & $2 \mathrm{ff}$ & tBuLi (2.0 equiv.) & & 5 & & $5 f$ & $72(26)$ \\
\hline 6 & & $n$ BuLi (1.2 equiv.) & -80 & 1 & & & $49(34)$ \\
\hline 7 & $b$ & tBuLi (2.0 equiv.) & -80 & 0.5 & & $5 d$ & $58(44)$ \\
\hline
\end{tabular}

[a] Isolated yields after centrifugal thin-layer chromatography purification.

Additionally, it has already been observed in previous reports that the influence of aryne precursors could also vary with the nature of the lithiated partner employed in the aryne coupling. In short, detailed examination considering the unique reactivity of heterocycles is clearly essential in view of further improvements. Finally, it is important to note that the concomitant presence of both $\mathrm{KCl}$ and $\mathrm{LiBr}$ - resulting from the use of $t \mathrm{BuLi}$ as the base in the metalation step of 3-bromopyridine $\mathbf{2} \mathbf{f}$ - is an important consideration with regard to the tremendous improvement observed for this compound (Table 7, entry 5) and promises interesting perspectives in view of further investigations on "salt effects".

\section{Conclusions}

This work reports the efficient synthesis of various heterobiaryl compounds based on the transition metal-free aryne coupling methodology. The effect of both electron-rich and electrondeficient heteroaromatics on the Het-Aryne coupling reaction along with the metalation route employed to access the corresponding heteroaryllithiums were examined. The results clearly showed the favorable influence of $\pi$-electron-rich fivemembered-ring heteroaromatics on the reaction. Additionally, detailed investigations of both ligand and salt effects on the model reaction developed with thiophene revealed fundamental effects of these additives on the reaction when performed in apolar media. Overall, the use of such compounds in the Het-Aryne coupling provided impressive enhancement of the yield for a range of various heterocycles. 
WILEY-VCH

\section{Experimental Section}

General Methods. All reactions were performed under argon atmosphere in oven- and flame-dried, argon-cooled glassware. All air- and moisturesensitive compounds were introduced via syringes through a rubber septum. ${ }^{1} \mathrm{H}$ and ${ }^{13} \mathrm{C}$ NMR spectra were recorded on a Bruker 200- or 400 $\mathrm{MHz}$ spectrometer with $\mathrm{CDCl}_{3}$ as solvent. Chemical shifts are reported in $\delta$ units (parts per million, ppm) and were measured relative to the signals for residual chloroform (7.26 ppm for ${ }^{1} \mathrm{H}$ NMR and $77.00 \mathrm{ppm}$ for ${ }^{13} \mathrm{C} \mathrm{NMR}$ ). Coupling constants $\mathrm{J}$ are given in $\mathrm{Hz}$. Coupling patterns are abbreviated as $\mathrm{s}$ (singlet), $\mathrm{d}$ (doublet), td (triplet of doublets), $\mathrm{m}$ (multiplet). MS experiments were recorded on a GCMS-QP 2010 spectrometer. Thin-layer chromatography (TLC) was carried out using $0.25 \mathrm{~mm}$ Merck silica-gel (60F254) plates and visualized under UV light. Centrifugal thin-layer chromatography purifications were performed on silica gel (silica gel 60 PF254 containing gypsum).

Reagents. All reagents were commercially available and used as received after adequate checks. $n \mathrm{BuLi}$ (1.6 $\mathrm{M}$ in hexane), $t \mathrm{BuLi}(1.7 \mathrm{M}$ in pentane) and $\mathrm{PhLi}(1.8 \mathrm{M}$ in cyclohexane/ndibutylether: $7 / 3$ ) were titrated prior to use against diphenylacetic acid in dry THF. Commercial grade anhydrous salts were dried on a MB25 Ohaus thermobalance before use. 2(Dimethylamino)ethanol (DMAE), diisopropylamine (DIA), $N, N, N^{\prime}, N^{\prime}-$ tetramethylethylenediamine $\quad$ (TMEDA), $\quad(S)-(-)-N$-methyl-2pyrrolidinylmethoxide (LiPM) and diethyleneglycol were freshly distilled and stored under argon over molecular sieves before use. DME and hexane were stored over sodium wire before use. THF and toluene were freshly distilled and stored under argon before use.

General Procedure for the Het-Aryne coupling in THF as solvent.

1,2-Dibromobenzene 1a (566.2 mg, $2.4 \mathrm{mmol}, 1.2$ equiv.) in THF (4 mL) was added to a solution of heteroaryllithium [2-Li] $(2.0 \mathrm{mmol}, 1.0$ equiv., for the preparation of [2-Li] see SI) in THF $(6 \mathrm{~mL})$ at $-50^{\circ} \mathrm{C}$. After $2 \mathrm{~h}$ of stirring, the reaction mixture was hydrolyzed with water $(15 \mathrm{~mL})$ at $-50{ }^{\circ} \mathrm{C}$ and was extracted with AcOEt $(3 \times 10 \mathrm{~mL})$. The combined organic layers were dried over $\mathrm{MgSO}_{4}$, and solvents were removed under reduced pressure. The crude product was purified by centrifugal chromatography to afford compound $3 \mathbf{a}-\mathbf{j}$.

General Procedure for the Het-Aryne coupling in toluene as solvent and in the presence of DME as ligand.

DME (L1A, $8.0 \mathrm{mmol}, 0.82 \mathrm{~mL}, 4.0$ equiv.) was added to a solution of heteroaryllithium [2-Li] $(2.0 \mathrm{mmol}, 1.0$ equiv., for the preparation of [2-Li] see $\mathrm{SI})$ in toluene $(6 \mathrm{~mL})$, at $-78^{\circ} \mathrm{C}$. The temperature was allowed to reach $-50{ }^{\circ} \mathrm{C}$ during $45 \mathrm{~min}$. and aryne precursor 1a-d (2.4 mmol, 1.2 equiv.) in toluene $(4 \mathrm{~mL})$ was added. After stirring for $2 \mathrm{~h}$ at $-50{ }^{\circ} \mathrm{C}$, the reaction mixture was hydrolyzed with water $(15 \mathrm{~mL})$ and was extracted with AcOEt $(3 \times 10 \mathrm{~mL})$. The combined organic layers were dried over $\mathrm{MgSO}_{4}$, and solvents were removed under reduced pressure. The crude product was purified by centrifugal chromatography to afford compound $\mathbf{3 b}, \mathbf{f}, \mathbf{j}$ and $\mathbf{5 b}$.

General Procedure for the Het-Aryne coupling in toluene as solvent, in the presence of $\mathrm{DME}$ as ligand and $\mathrm{KCl}$ as salt additive.

To a solution of heteroaryllithium [2-Li] $(2.0 \mathrm{mmol}, 1.0$ equiv., for the preparation of [2-Li] see $\mathrm{SI})$ in toluene $(6 \mathrm{~mL})$ at the metalation temperature $T^{\circ} \mathrm{C}$ (for $\mathrm{T}^{\circ} \mathrm{C}$, see $\mathrm{SI}$ ) was added dried $\mathrm{KCl}(10.0 \mathrm{mmol}, 745.5$ $\mathrm{mg}, 5.0$ equiv.). After $5 \mathrm{~min}$. of stirring, DME (L1A, $8.0 \mathrm{mmol}, 0.82 \mathrm{~mL}, 4.0$ equiv.) was subsequently added to the reaction mixture at the same temperature $T{ }^{\circ} \mathrm{C}$. The temperature was then allowed to reach $-50{ }^{\circ} \mathrm{C}$ during $45 \mathrm{~min}$. and 2-bromoiodobenzene 1b $(679.0 \mathrm{mg}, 2.4 \mathrm{mmol}, 1.2$ equiv.) in toluene $(4 \mathrm{~mL})$ was added. After stirring for $2 \mathrm{~h}$ at $-50{ }^{\circ} \mathrm{C}$, the reaction mixture was hydrolyzed with water $(15 \mathrm{~mL})$ and was extracted with AcOEt $(3 \times 10 \mathrm{~mL})$. The combined organic layers were dried over
$\mathrm{MgSO}_{4}$, and solvents were removed under reduced pressure. The crude product was purified by centrifugal chromatography to afford compound 5a-g.

2-(2-Bromophenyl)furan (3a). ${ }^{[96]}$ Colorless oil, $245 \mathrm{mg}, 55 \%$ yield. ${ }^{1} \mathrm{H}$ NMR $\left(400 \mathrm{MHz}, \mathrm{CDCl}_{3}\right) \delta 6.55$ (dd, $\left.J=3.4 \mathrm{~Hz}, J=1.8 \mathrm{~Hz}, 1 \mathrm{H}\right), 7.11-7.20$ $(\mathrm{m}, 2 \mathrm{H}), 7.38(\mathrm{dd}, J=7.4 \mathrm{~Hz}, J=1.2 \mathrm{~Hz}, 1 \mathrm{H}), 7.54(\mathrm{dd}, J=1.8 \mathrm{~Hz}, J=0.7$ $\mathrm{Hz}, 1 \mathrm{H}), 7.66(\mathrm{~d}, J=1.1 \mathrm{~Hz}, 1 \mathrm{H}), 7.82(\mathrm{dd}, J=7.9 \mathrm{~Hz}, J=1.7 \mathrm{~Hz}, 1 \mathrm{H}) ;{ }^{13} \mathrm{C}$ NMR $\left(100 \mathrm{MHz}, \mathrm{CDCl}_{3}\right) \delta 110.6,111.4,119.7,127.4,128.5,128.8,131.3$, 134.1, 142.2, 151.3; MS (El): m/z 222 ([M] $\left.{ }^{+}, 8\right), 115$ (31), 87 (18), 74 (38), 63 (38), 50 (50), 39 (100).

3-(2-Bromophenyl)thiophene (3b). ${ }^{[44]}$ Colorless oil, $287 \mathrm{mg}, 60 \%$ yield.

3-(2-Bromophenyl)benzo[b]thiophene (3c). ${ }^{[97]}$ Colorless oil, $237 \mathrm{mg}$, $41 \%$ yield. ${ }^{1} \mathrm{H}$ NMR $\left(400 \mathrm{MHz}, \mathrm{CDCl}_{3}\right) \delta 7.09-7.16(\mathrm{~m}, 1 \mathrm{H}), 7.22-7.32(\mathrm{~m}$, $3 \mathrm{H}$ ), 7.40 (s, 1H), 7.45 (dd, $J=7.7 \mathrm{~Hz}, J=1.7 \mathrm{~Hz}, 1 \mathrm{H}$ ), 7.61 (dd, $J=8.0$ $\mathrm{Hz}, J=1.1 \mathrm{~Hz}, 1 \mathrm{H}), 7.74(\mathrm{ddd}, J=12.8 \mathrm{~Hz}, J=7.5,1.2 \mathrm{~Hz}, 2 \mathrm{H}) ;{ }^{13} \mathrm{C}$ NMR $\left(100 \mathrm{MHz}, \mathrm{CDCl}_{3}\right) \delta 122.2,123.1,124.0,124.5,127.5,129.4,129.6,129.3$, 132.3, 133.7, 135.4, 139.8, 140.3, 141.2; MS (EI): $m / z 290$ ([M] $\left.]^{+}, 100\right), 289$ (16), 288 (97), 208 (28), 165 (89), 104 (25), 83 (10).

2-(2-Bromophenyl)benzo[b]thiophene (3d). [98] White solid, $260 \mathrm{mg}$ $45 \%$ yield. ${ }^{1} \mathrm{H}$ NMR $\left(400 \mathrm{MHz}, \mathrm{CDCl}_{3}\right) \delta^{1} \mathrm{H} \mathrm{NMR}\left(400 \mathrm{MHz}, \mathrm{CDCl}_{3}\right) \delta 7.26-$ $7.49(\mathrm{~m}, 6 \mathrm{H}), 7.57-7.64(\mathrm{~m}, 1 \mathrm{H}), 7.81(\mathrm{~d}, J=7.6 \mathrm{~Hz}, 1 \mathrm{H}), 7.99-8.01(\mathrm{~m}$, $1 \mathrm{H}) ;{ }^{13} \mathrm{C}$ NMR $\left(100 \mathrm{MHz}, \mathrm{CDCl}_{3}\right) \delta 122.1,123.2,123.9,124.3,124.5$, $124.7,127.5,129.6,132.1,133.6,135.5,139.7,140.2,142.4 ; \mathrm{MS}(\mathrm{EI}): \mathrm{m} / \mathrm{z}$ 288 ([M] $\left.{ }^{+}, 53\right), 208$ (37), 165 (65), 139 (18), 104 (21), 87 (26), 74 (54), 50 (72), 39 (100).

3-(2-Bromophenyl)pyridine (3f). Colorless solid, $122 \mathrm{mg}, 26 \%$ yield. ${ }^{1} \mathrm{H}$ NMR $\left(400 \mathrm{MHz}, \mathrm{CDCl}_{3}\right){ }^{1} \mathrm{H}$ NMR $\left(400 \mathrm{MHz}, \mathrm{CDCl}_{3}\right) \delta 7.21$ (dd, $J=7.9,1.8$ $\mathrm{Hz}, 1 \mathrm{H}), 7.28-7.35(\mathrm{~m}, 3 \mathrm{H}), 7.65(\mathrm{dd}, J=8.0,1.2 \mathrm{~Hz}, 1 \mathrm{H}), 7.69-7.72(\mathrm{~m}$, $1 \mathrm{H}), 8.59(\mathrm{~s}, 1 \mathrm{H}), 8.64(\mathrm{~s}, 1 \mathrm{H}) ;{ }^{13} \mathrm{C} \mathrm{NMR}\left(100 \mathrm{MHz}, \mathrm{CDCl}_{3}\right) \delta 122.8,127.7$ 129.6, 131.2, 133.3, 133.5, 136.6, 136.8, 139.0, 148.8, 149.9; MS (EI): $\mathrm{m} / \mathrm{z}$ $233\left([\mathrm{M}]^{+}, 68\right), 154$ (45), 127 (57), 101 (24), 87 (37), 74 (99), 63 (68), 39 (100). HRMS (ESI/Q-TOF) m/z: $[\mathrm{M}+\mathrm{H}]^{+}$calcd for $\mathrm{C}_{11} \mathrm{H}_{9} \mathrm{BrN} 233.9913$; found 233.9892 .

2-(2-Bromophenyl)-N,N-dimethylpyridin-4-amine (3g). Yellow oil, 83 $\mathrm{mg}, 15 \%$ yield. ${ }^{1} \mathrm{H}$ NMR $\left(400 \mathrm{MHz}, \mathrm{CDCl}_{3}\right) \delta 2.98(\mathrm{~s}, 6 \mathrm{H}), 6.45-6.47(\mathrm{~m}$ $1 \mathrm{H}), 6.72(\mathrm{~d}, J=2.6 \mathrm{~Hz}, 1 \mathrm{H}), 7.17(\mathrm{td}, J=7.7 \mathrm{~Hz}, J=1.8 \mathrm{~Hz}, 1 \mathrm{H}), 7.33(\mathrm{td}$, $J=7.5 \mathrm{~Hz}, J=1.2 \mathrm{~Hz}, 1 \mathrm{H}), 7.45-7.52(\mathrm{~m}, 1 \mathrm{H}), 7.61(\mathrm{dd}, J=8.0 \mathrm{~Hz}, J=1.0$ $\mathrm{Hz}, 1 \mathrm{H}), 8.28(\mathrm{~d}, J=6.0 \mathrm{~Hz}, 1 \mathrm{H}) ;{ }^{13} \mathrm{C} \mathrm{NMR}\left(100 \mathrm{MHz}, \mathrm{CDCl}_{3}\right) \delta 39.2,105.5$, 107.6, 121.9, 127.3, 129.3, 131.3, 133.1, 142.4, 149.3, 154.2, 158.5; MS (EI): m/z 276 ([M] $\left.]^{+}, 100\right), 198$ (50), 182 (54), 121 (27), 77 (39), 39 (25); HRMS (ESI/Q-TOF) m/z: [M + H] $]^{+}$calcd for $\mathrm{C}_{13} \mathrm{H}_{14} \mathrm{BrN}_{2} 277.0335$; found 277.0324

2-Bromo-2'-methoxybiphenyl (3i). ${ }^{[99]}$ Colorless oil, $146 \mathrm{mg}, 31 \%$ yield ${ }^{1} \mathrm{H}$ NMR $\left(400 \mathrm{MHz}, \mathrm{CDCl}_{3}\right) \delta 3.70(\mathrm{~s}, 3 \mathrm{H}), 6.86-6.97(\mathrm{~m}, 2 \mathrm{H}), 7.10$ (ddd, J $=13.6 \mathrm{~Hz}, J=7.4 \mathrm{~Hz}, J=1.8 \mathrm{~Hz}, 2 \mathrm{H}), 7.18-7.35(\mathrm{~m}, 3 \mathrm{H}), 7.57(\mathrm{dd}, J=8.0$ $\mathrm{Hz}, J=1.0 \mathrm{~Hz}, 1 \mathrm{H}) ;{ }^{13} \mathrm{C} \mathrm{NMR}\left(100 \mathrm{MHz}, \mathrm{CDCl}_{3}\right) \delta 55.6,111.0,120.3,124.3$, $127.0,128.7,129.4,130.3,130.9,131.6,132.5,139.9,156.6$.

2-Bromobiphenyl (3j). ${ }^{[44]}$ Colorless oil, $204 \mathrm{mg}, 44 \%$ yield. ${ }^{1} \mathrm{H}$ NMR (400 $\mathrm{MHz} \mathrm{CDCl}_{3}$ ) $\delta 7.08$ (tdd, $J=9.3 \mathrm{~Hz}, J=8.1 \mathrm{~Hz}, J=1.5 \mathrm{~Hz}, 2 \mathrm{H}$ ), 7.21 (dd $J=7.5 \mathrm{~Hz}, J=1.8 \mathrm{~Hz}, 1 \mathrm{H}), 7.27-7.36(\mathrm{~m}, 2 \mathrm{H}), 7.38-7.46(\mathrm{~m}, 2 \mathrm{H}), 7.51(\mathrm{dt}$, $J=7.0 \mathrm{~Hz}, J=3.6 \mathrm{~Hz}, 1 \mathrm{H}), 7.58(\mathrm{dd}, J=7.8 \mathrm{~Hz}, J=1.2 \mathrm{~Hz}, 1 \mathrm{H}), 7.73$ (dd $J=8.4 \mathrm{~Hz}, J=1.2 \mathrm{~Hz}, 1 \mathrm{H}) ;{ }^{13} \mathrm{C} \mathrm{NMR}\left(100 \mathrm{MHz}, \mathrm{CDCl}_{3}\right) \delta 123.6,126.8$, 127.2, 128.7, 129.5, 130.7, 131.1, 131.3, 132.3, 132.7, 140.0, 142.1; MS (EI): $m / z 234$ ([M] $\left.{ }^{+}, 33\right), 152$ (65), 126 (11), 87 (14), 74 (56), 63 (52), 50 (87), 39 (100).

2-(2-lodophenyl)furan (5a). Colorless solid, $329 \mathrm{mg}, 61 \%$ yield. Derivative 5 a was very unstable, analyses were performed on an analytical 
WILEY-VCH

sample. ${ }^{1} \mathrm{H}$ NMR $\left(400 \mathrm{MHz}, \mathrm{CDCl}_{3}\right) \delta 6.53(\mathrm{dd}, J=3.4 \mathrm{~Hz}, J=1.8 \mathrm{~Hz}, 1 \mathrm{H})$, 6.96-7.01 (m, 1H), $7.05(\mathrm{dd}, J=3.4 \mathrm{~Hz}, J=0.6 \mathrm{~Hz}, 1 \mathrm{H}), 7.35-7.47(\mathrm{~m}, 2 \mathrm{H})$, $7.64(\mathrm{dd}, J=7.8 \mathrm{~Hz}, J=1.7 \mathrm{~Hz}, 1 \mathrm{H}), 7.98(\mathrm{dd}, J=8.0 \mathrm{~Hz}, J=1.2 \mathrm{~Hz}, 1 \mathrm{H})$; ${ }^{13} \mathrm{C}$ NMR $\left(100 \mathrm{MHz}, \mathrm{CDCl}_{3}\right) \delta 94.5,109.7,111.1,128.1,129.0,129.4$, 135.4, 140.8, 142.3, 153.6; MS (EI): $\mathrm{m} / \mathrm{z} 270$ ([M] $\left.{ }^{+}, 100\right), 143$ (12), 115 (63), 89 (24), 63 (22). HRMS (ESI/Q-TOF) m/z: $\left[\mathrm{M}+\mathrm{H}^{+}\right.$calcd for $\mathrm{C}_{10} \mathrm{H}_{8} \mathrm{IO}$ 270.9614 ; found 270.9610 .

3-(2-lodophenyl)thiophene (5b). Colorless solid, $509 \mathrm{mg}, 89 \%$ yield. ${ }^{1} \mathrm{H}$ $\operatorname{NMR}\left(400 \mathrm{MHz}, \mathrm{CDCl}_{3}\right) \delta$ 6.99-7.12 (m, 1H), 7.12-7.46 (m, 5H), $7.98(\mathrm{~d}, J$ $=7.9 \mathrm{~Hz}, 1 \mathrm{H}) ;{ }^{13} \mathrm{C}$ NMR $\left(100 \mathrm{MHz}, \mathrm{CDCl}_{3}\right) \delta 99.8,122.8,124.9,127,3$, 128.6, 129.1, 131.4, 136.6, 141.5, 145.7; MS (El): $\mathrm{m} / \mathrm{z} 286$ ([M] $\left.{ }^{+}, 77\right), 159$ (13), 115 (100), 89 (51), 39 (54). HRMS (ESI/Q-TOF) m/z: [M + H] $]^{+}$calcd for $\mathrm{C}_{10} \mathrm{H}_{8} \mathrm{IS} 286.9386$, found $\mathrm{m} / \mathrm{z} 286.9357$.

2-(2-lodophenyl)benzo[b]thiophene (5c). ${ }^{[96]}$ Colorless oil, $410 \mathrm{mg}, 61 \%$ yield. ${ }^{1} \mathrm{H}$ NMR $\left(400 \mathrm{MHz}, \mathrm{CDCl}_{3}\right) \delta$ 7.08-7.14 $(\mathrm{m}, 1 \mathrm{H}), 7.41-7.49(\mathrm{~m}, 4 \mathrm{H})$, 7.56 (dd, $J=7.7 \mathrm{~Hz}, J=1.6 \mathrm{~Hz}, 1 \mathrm{H}$ ), 7.82-7.96 (m, 2H), 8.06 (dd, $J=8.0$ $\mathrm{Hz}, J=1.1 \mathrm{~Hz}, 1 \mathrm{H}) ;{ }^{13} \mathrm{C} \mathrm{NMR}\left(100 \mathrm{MHz}, \mathrm{CDCl}_{3}\right) \delta 99.3,122.3,124.1$, $124.5,124.7,128.2,129.9,131.6,139.6,139.8,139.9,140.2,140.4$, 145.2; HRMS (ESI/Q-TOF) m/z: $[\mathrm{M}+\mathrm{H}]^{+} 336,9543$ calcd for $\mathrm{C}_{14} \mathrm{H}_{10} \mathrm{IS}$, found $\mathrm{m} / \mathrm{z} 336,9552$.

2-lodobiphenyl (5d). ${ }^{[100]}$ Colorless oil, $325 \mathrm{mg}, 58 \%$ yield. ${ }^{1} \mathrm{H}$ NMR $(400$ $\left.\mathrm{MHz}, \mathrm{CDCl}_{3}\right) \delta 7.12-7.08(\mathrm{~m}, 1 \mathrm{H}), 7.23$ (ddd, $J=10.8,7.6,1.8 \mathrm{~Hz}, 2 \mathrm{H}$ ), 7.29 (dd, $J=7.7,2.0 \mathrm{~Hz}, 1 \mathrm{H}), 7.41$ (dtd, $J=8.7,7.5,1.2 \mathrm{~Hz}, 3 \mathrm{H}), 7.67$ (d, $J=1.0 \mathrm{~Hz}, 1 \mathrm{H}), 7.96(\mathrm{dd}, J=7.9,1.0 \mathrm{~Hz}, 1 \mathrm{H}) ;{ }^{13} \mathrm{C} \mathrm{NMR}\left(100 \mathrm{MHz}, \mathrm{CDCl}_{3}\right)$ $\delta$ 99.5, 123.5, 127.2, 128.0, 129.3, 129.5, 131.0, 132.6, 138.9, 145.0, 146.1; MS (EI): $m / z 281$ (16), 280 ([M] $\left.{ }^{+}, 75\right), 152$ (100), 126 (25), 86 (25), 76 (74), 51 (19), 39 (38).

3-(2-lodophenyl)pyridine (5f). ${ }^{1011]}$ Yellow oil, $405 \mathrm{mg}, 72 \%$ yield. ${ }^{1} \mathrm{H}$ NMR $\left(400 \mathrm{MHz}, \mathrm{CDCl}_{3}\right) \delta 7.12$ (ddd, $J=7.9 \mathrm{~Hz}, J=7.5 \mathrm{~Hz}, J=1.7 \mathrm{~Hz}, 1 \mathrm{H}$ ), 7.33-7.23 (m, 3H), 7.46-7.39 (m, 2H), $7.71(\mathrm{dd}, J=8.0 \mathrm{~Hz}, J=1.0 \mathrm{~Hz}, 1 \mathrm{H})$, $7.98(\mathrm{dd}, J=8.0 \mathrm{~Hz}, J=1.0 \mathrm{~Hz}, 1 \mathrm{H}) ;{ }^{13} \mathrm{C} \mathrm{NMR}\left(100 \mathrm{MHz}, \mathrm{CDCl}_{3}\right) \delta 99.5$, $123.5,127.2,128.0,129.3,129.5,130.0,131.0,132.6,138.9,145.0$, 146.1; MS (EI): m/z 281 ([M+] 23), 206 (100), 127 (97), 104 (30), 91 (76), 75 (51), 37 (39).

2-lodo-2'-methoxybiphenyl (5g). ${ }^{[102]}$ Colorless oil, $303 \mathrm{mg}, 49 \%$ yield. ${ }^{1} \mathrm{H}$ $\operatorname{NMR}\left(400 \mathrm{MHz}, \mathrm{CDCl}_{3}\right) \delta 3.84(\mathrm{~s}, 3 \mathrm{H}), 7.02-7.12(\mathrm{~m}, 3 \mathrm{H}), 7.19$ (dd, $J=7.4$ $\mathrm{Hz}, J=1.8 \mathrm{~Hz}, 1 \mathrm{H}), 7.34(\mathrm{dd}, J=7.6 \mathrm{~Hz}, J=1.7 \mathrm{~Hz}, 1 \mathrm{H}), 7.43-7.48(\mathrm{~m}$, $2 \mathrm{H}), 8.00(\mathrm{dd}, J=8.0 \mathrm{~Hz}, J=1.0 \mathrm{~Hz}, 1 \mathrm{H}) ;{ }^{13} \mathrm{C} \mathrm{NMR}\left(100 \mathrm{MHz}, \mathrm{CDCl}_{3}\right) \delta$ $55.7,100.7,111.2,120.5,120.7,128.0,128.8,129.5,130.8,133.5,138.9$, 144.2, 156.4 .

\section{Acknowledgments}

We gratefully acknowledge the French Agence Nationale pour la Recherche (ANR) (grant number ANR-14-CE06-0003-01, ChirNoCat), CNRS and Université de Lorraine for financial support. We thank Sandrine Adach and Fabien Lachaud for technical support and recording mass spectra (UMR L2CM 7053).

Keywords: - reaction mechanisms $\cdot$ heterocyclic chemistry aryne $\cdot$ salt effect $\cdot$ ligand effect

[1] J. J. Mason, J. Bergman, T. Janosik, J. Nat. Prod. 2008, 71, 1447-1450. [2] G. D. Reddy, S.-J. Park, H. M. Cho, T.-J. Kim, M. E. Lee, J. Med. Chem. 2012, 55, 6438-6444

[3] J. Yamaguchi, K. Itami, Bull. Chem. Soc. Jpn. 2017, 90, 367-383.

[4] I. McCulloch, M. Heeney, M. L. Chabinyc, D. DeLongchamp, J. Kline, M. Cölle, W. Duffy, D. Fischer, D. Gundlach, B. Hamadani, R. Hamilton, L.
Richter, A. Salleo, M. Shkunov, D. Sparrowe, S. Tierney, W. Zhang. Adv. Mater. 2009, 21, 1091-1109.

[5] L.-C. Campeau, K. Fagnou, Chem. Soc. Rev. 2007, 36, 1058-1068.

[6] D. Zhao, J. You, C. Hu, Chem. Eur. J. 2011, 17, 5466-5492.

[7] R. Rossi, M. Lessi, C. Manzini, G. Marianetti, F. Bellina, Adv. Synth. Catal. 2015, 357, 3777-3814.

[8] M. Koji, D. Toshifumi, K. Yasuyuki, Synlett 2017, 28, 1680-1694.

[9] I. Alkorta, J. Elguero, C. Roussel, N. Vanthuyne, P. Piras, Adv. Heterocycl. Chem., 2012, 105, 1-188.

[10] E. Kumarasamy, R. Raghunathan, M. P. Sibi, J. Sivaguru, Chem. Rev. 2015, 115, 11239-11300.

[11] D. Bonne, J. Rodriguez, J. Chem. Commun. 2017, 53, 12385-12393.

[12] D. Bonne, J. Rodriguez, Eur. J. Org. Chem. 2018, 2417-2431.

[13] K. Yamaguchi, J. Yamaguchi, A. Studer, K. Itami, Chem. Sci. 2012, 3, 2165-2169.

[14] K. Yamaguchi, H. Kondo, J. Yamaguchi, K. Itami, Chem. Sci. 2013, 4, 3753-3757.

[15] V. S. Raut, M. Jean, N. Vanthuyne, C. Roussel, T. Constantieux, C. Bressy, X. Bugaut, D. Bonne, J. Rodriguez, J. Am. Chem. Soc. 2017, 139, 2140-2143.

[16] L. Zhang, J. Zhang, J. Ma, D.-J. Cheng, B. Tan, J. Am. Chem. Soc. 2017, 139, 1714-1717.

[17] J. Rae, J. Frey, S. Jerhaoui, S. Choppin, J. Wencel-Delord, F. Colobert, ACS, Catal. 2018, 8, 2805-2809.

[18] X. Chen, L. Zhou, Y. Li, T. Xie, S. Zhou, J. Org. Chem. 2013, 79, 230239.

[19] H. Andersson, T. S.-L. Banchelin, S. Das, R. Olsson, F. Almqvist, Chem Commun. 2010, 46, 3384-3386.

[20] F.-F. Zhuo, W.-W. Xie, Y.-X. Yang, Y.-X. Zhang, P. Wang, R. Yuan, C.S. Da, J. Org. Chem. 2013, 78, 3243-3249.

[21] C. M. Holden, S. M. A. Sohel, M. F. Greaney, Angew. Chem. Int. Ed. 2016, 55, 2450-2453.

[22] T. Yanagi, S. Otsuka, Y. Kasuga, K. Fujimoto, K. Murakami, K. Nogi, H. Yorimisu, A. Osuka, J. Am. Chem. Soc. 2016, 138, 14582-14585.

[23] L. Minuti, F. Piazzolla, A. Temperini, Eur. J. Org. Chem. 2017, 5370-5377.

[24] Y. Kita, K. Morimoto, M. Ito, C. Ogawa, A. Goto, T. Dohi, J. Am. Chem. Soc. 2009, 131, 1668-1669.

[25] S. Yanagisawa, K. Ueda, T. Taniguchi, K. Itami, Org. Lett. 2008, 10, 4673-4676.

[26] Q. Song, D. Zhang, Q. Zhu, Y. Xu, Org. Lett. 2014, 16, 5272-5274.

[27] O. Vakuliuk, B. Koszarna, D. T. Gryko, Eur. J. Org. Chem. 2011, 28542859.

[28] F. Leroux, M. Schlosser, Angew. Chem. Int. Ed. 2002, 41, 4272-4274.

[29] F. R. Leroux, L. Bonnafoux, C. Heiss, F. Colobert, D. A. Lanfranchi, Adv. Synth. Catal. 2007, 349, 2705-2713.

[30] L. Bonnafoux, F. Colobert, F. R. Leroux, Synlett 2010, 19, 2953-2955.

[31] L. Bonnafoux, R. Gramage-Doria, F. Colobert, F. R. Leroux, Chem. Eur. J. 2011, 17, 11008-11016.

[32] V. Diemer, M. Begaud, F. R. Leroux, F. Colobert, Eur. J. Org. Chem. 2011, 341-354.

[33] V. Diemer, J. S. Garcia, F. R. Leroux, F. Colobert, J. Fluorine Chem. 2012, 134, 146-155.

[34] L. Bonnafoux, F. R. Leroux, F. Colobert, Beilstein J. Org. Chem. 2011, 7, 1278-1287.

[35] F. R. Leroux, A. Berthelot, L. Bonnafoux, A. Panossian, F. Colobert, Chem. Eur. J. 2012, 18, 14232-14236.

[36] B. Yalcouye, S. Choppin, A. Panossian, F. R. Leroux, F. Colobert, Eur. J. Org. Chem. 2014, 6285-6294.

[37] D. Augros, B. Yalcouye, S. Choppin, M. Chessé, A. Panossian, F. R. Leroux, Eur. J. Org. Chem. 2017, 497-503.

[38] A. Berthelot-Bréhier, A. Panossian, F. Colobert, F. R. Leroux, Org. Chem. Front. 2015, 2, 634-644.

[39] B. Yalcouye, A. Berthelot-Bréhier, D. Augros, A. Panossian, S. Choppin, M. Chessé, F. Colobert, F. R. Leroux, Eur. J. Org. Chem. 2016, 725-732.

[40] D. Augros, B. Yalcouye, A. Berthelot-Bréhier, M. Chessé, S. Choppin, A. Panossian, F. R. Leroux, Tetrahedron 2016, 72, 5208-5220.

[41] A. Panossian, F. R. Leroux, Chimia. 2016, 70, 43-47. 
[42] F. R. Leroux, A. Panossian, D. Augros, C. R. Chimie 2017, 682-692.

[43] J. Bortoluzzi, V. Jha, G. Levitre, M. J. Fer, J. Berreur, G. Masson, A. Panossian, F. R. Leroux, J. Org. Chem. 2018, 83, 7751-7761.

[44] C. Demangeat, T. Saied, R. Ramozzi, F. Ingrosso, M. Ruiz-Lopez, A. Panossian, F. R. Leroux, Y. Fort, C. Comoy, Eur. J. Org. Chem. 2019 547-556.

[45] J. Clayden, Organolithiums: Selectivity for synthesis 2002, chap. 1, Tetrahedron Organic Chemistry Series.

[46] H. J. Reich, Chem. Rev. 2013, 113, 7130-7178.

[47] F. Leroux, J. Mortier, Directed metallation of arenes with organolithiums, lithium amides, and superbases, in "Arene Chemistry: Reaction Mechanisms and Methods for Aromatic Compounds" 2016, Mortier, John Whiley \& Sons Inc. p.743-776.

[48] E. Vedejs, X. Chen, J. Am. Chem. Soc. 1996, 118, 1809-1810.

[49] S. Kessar, P. Singh, Chem. Rev. 1997, 97, 721-738.

[50] H. Pellissier, M. Santelli, Tetrahedron 2003, 59, 701-730.

[51] R. Sanz, Org. Prep. Proced. Int. 2008, 40, 215-291.

[52] Y. Fang, Y. Zheng, Z. Wang, Eur. J. Org. Chem. 2012, 1495-1498.

[53] S. S. Bhojgude, T. Kaicharla, A. T. Biju, Org. Lett. 2013, 15, 5452-5455.

[54] P. Huang, B.-Y. He, H.-M. Wang, J.-M. Lu, Synthesis 2015, 47, 221-227.

[55] M. Shindo, K. Koga, K. Tomioka, J. Org. Chem. 1998, 63, 9351-9357.

[56] A. Alexakis, A. Tomassini, S. Leconte, Tetrahedron, 2004, 60, 9479-9484.

[57] J. Praz, L. Guénée, S. Aziz, A. Berkessel, A. Alexakis, Adv. Synth. Catal. 2012, 354, 1780-1790.

[58] P. Gros, Y. Fort, G. Quéguiner, P. Caubère, Tetrahedron Lett. 1995, 36, 4791-4794.

[59] P. Gros, Y. Fort, P. Caubère, J. Chem. Soc. Perkin Trans. 1 1997, $3071-$ 3080.

[60] P. C. Gros, Y. Fort, Eur. J. Org. Chem. 2002, 3375-3383.

[61] P. C. Gros, Y. Fort, Eur. J. Org. Chem. 2009, 4199-4209.

[62] S. Schade, G. Boche, J. Organomet. Chem. 1998, 550, 381-395.

[63] S. Schade, G. Boche, J. Organomet. Chem. 1998, 550, 359-379.

[64] S. E. Denmark, N. Nakajima, O. J.-C. Nicaise, J. Am. Chem. Soc. 1994, 116, 8797-8798.

[65] S. E. Denmark, N. Nakajima, C. M. Stiff, O. J.-C. Nicaise, M. Kranz, Adv. Synth. Catal. 2008, 350, 1023-1045.

[66] D. J. Gallagher, S. Wu, N. A. Nikolic, P. Beak, J. Org. Chem. 1995, 60, 8148-8154.

[67] Y. S. Park, G. A. Weisenburger, P. Beak, J. Am. Chem. Soc. 1997, 119, 10537-10538.

[68] I. Inoue, M. Shindo, K. Koga, K. Tomioka, Tetrahedron, 1994, 50, 44294438.

[69] Y. Yamamoto, H. Nasu, K. Tomioka, Tetrahedron, 2013, 69, 3836-3840.

[70] M. Chrzanowwska, J. Sokolowski, Tetrahedron: Asymmetry 2001, 12, 1435-1440.

[71] S. Desjardins, K. Flinois, H. Oulyadi, D. Davoust, C. Giessner-Prettre, O. Parisel, J. Maddaluno, Organometallics, 2003, 22, 4090-4097.

[72] B. Lecachey, H. Oulyadi, P. Lameiras, A. Harrison-Marchand, H. Gérard, J. Maddaluno, J. Org. Chem. 2010, 75, 5976-5983.

[73] T. Fox, H. Hausmann, H. Güunther, Magn. Reson. Chem. 2004, 42, 788794.

[74] P. L. Hall, J. H. Gilchrist, A. T. Harrison, D. J. Fuller, D. B. Collum, J. Am. Chem. Soc. 1991, 113, 9575-9585.

[75] F. E. Romesberg, D. B. Collum, J. Am. Chem. Soc. 1994, 116, $9187-$ 9197.

[76] F. E. Romesberg, D. B. Collum, J. Am. Chem. Soc. 1994, 116, 91989202.

[77] K. W. Henderson, A. E. Dorigo, Q.-Y. Liu, P. G. Williard, P. v. R. Schleyer, P. R. Bernstein, J. Am. Chem. Soc. 1996, 118, 1339-1347.

[78] W. Clegg, J. C. Greer, J. M. Hayes, F. S. Mair, P. M. Nolan, P. A. O'Neil, Inorg. Chim. Acta 1997, 258, 1-9.

[79] L. Pratt, M. Bull. Chem. Soc. Jpn. 2005, 78, 890-898.

[80] A. M. Bruneau, L. Liou, D. B. Collum, J. Am. Chem. Soc. 2014, 136, 2885-2891.

[81] Y. Gimbert, D. Lesage, C. Fressigné, J. Maddaluno, J. Org. Chem. 2017, 82, 8141-8147.

[82] H. J. S. Winkler, H. Winkler, J. Am. Chem. Soc. 1966, 88, 969-974.
[83] T. L. Rathman, W. F. Bailey, Org. Process. Res. Dev. 2009, 13, 144-151.

[84] W. F. Bailey, X. Jiang, Tetrahedron 2005, 61, 3183-3194.

[85] E. Hevia, R. E. Mulvey, Angew. Chem. Int. Ed. 2011, 5, 6448-6450.

[86] D. R. Armonstrong, W. Clegg, P. Garcia-Alvarez, A. R. Kennedy, M. D. McCall, L. Russo, E. Hevia, Chem. Eur. J. 2011, 17, 8333-8341.

[87] A. S. Galiano-Roth, Y. J. Kim, J. H. Gilchrist, A. T. Harrison, D. J. Fuller, D. B. Collum, J. Am. Chem. Soc. 1991, 113, 5053-5055.

[88] M. Ye, S. Logaraij, L. M. Jackman, K. Hillegass, K. A. Hirsh, A. M. Bolliger, A. L. Grosz, V. Mani, Tetrahedron 1994, 50, 6109-6116.

[89] T. Yasukata, K. Koga, Tetrahedron: Asymmetry 1993, 4, 35-38.

[90] A. Yanagisawa, T. Kikuchi, H. Yamamoto, Synlett, 1998, 174-176.

[91] G. Asensio, P. A. Aleman, L. R. Domingo, M. Medio-Simon, Tetrahedron Lett. 1998, 39, 3277-3280.

[92] B. J. Bunn, N. S. Simpkins, J. Org. Chem. 1993, 58, 533-534.

[93] M. Majewski, R. Lazny, P. Nowak, Tetrahedron Lett. 1995, 36, 54655468.

[94] K. Sugasawa, M. Shindo, H. Noguchi, K. Koga, Tetrahedron Lett. 1996, 37, 7377-7380.

[95] L. Gupta, A. C. Hoepker, K. J. Singh, D. B. Collum, J. Org. Chem. 2009, 74, 2231-2233.

[96] J. Wen, J. Zhang, S.-Y. Chen, J. Li, X.-Q. Yu, Angew. Chem. Int. Ed. 2008, 47, 8897-8900.

[97] M. Kienle, A. Unsinn, P. Knochel, Angew. Chem. Int. Ed. 2010, 49, 47514754.

[98] T. Truong, M. Mesgar, K. K. A. Le, O. Daugulis, J. Am. Chem. Soc. 2014, 136, 8568-8576.

[99] K. V. Kutonova, N. Jung, M. E. Trusova, V. D. Filimonov, P. S. Postnikov, S. Bräse, Synthesis 2017, 19, 1680-1688.

[100] S. Y. Cho, A. C. Grimsdale, D. J. Jones, S. E. Watkins, A. B. Holmes, J. Am. Chem. Soc. 2007, 129, 11910-11911.

[101] T. L. Andersen, S. D. Friis, H. Audrain, P. Nordeman, G. Antoni, T. Skrydstrup, J. Am. Chem. Soc. 2015, 137, 1548-1555.

[102] R. C. Fuson, R. Albright, J. Am. Chem. Soc. 1959, 81, 487-490. 
WILEY-VCH

\section{Entry for the Table of Contents}

\section{FULL PAPER}

We disclose for the first time an efficient route for the construction of various heterobiaryl backbones in fair to excellent yields using the Aryne coupling methodology. This study outlined the remarkable effect of external chelating ligands and salt additives on the heterocyclic partner reactivity in the aryne coupling reaction.

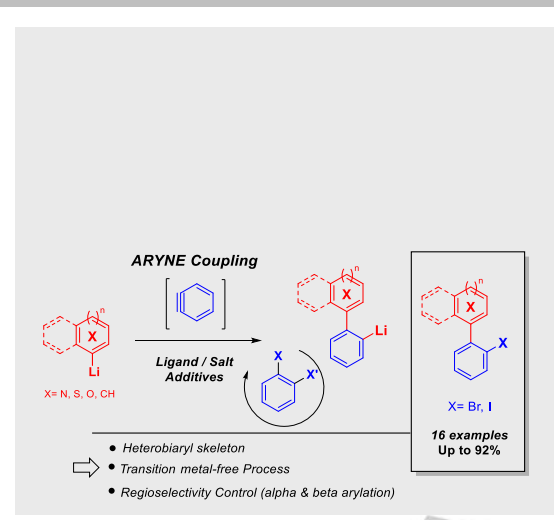

Heterobiaryls • Het-aryne coupling *

Tarak Saied, Catherine Demangeat, Armen Panossian, Frédéric R. Leroux, Yves Fort, Corinne Comoy. *

Page No. - Page No.

Transition-Metal-Free Heterobiaryl Synthesis via Aryne Coupling 